\title{
Juxta-articular myxoma of the wrist
}

\begin{abstract}
Author:
Andrew J. van den Heever ${ }^{1}$

Affiliation:

${ }^{1}$ Tuft and Partners

Incorporated Radiologists,

Cape Town, South Africa

Correspondence to:

Andrew van den Heever

Email:

andrew.vdh@tuft.co.za

Postal address:

PO Box 461, Plumstead 7801,

South Africa

Dates:

Received: 09 June 2014

Accepted: 06 Nov. 2014

Published: 11 Dec. 2014

How to cite this article: Van den Heever, A. Juxtaarticular myxoma of the wrist. S Afr J Rad. 2014;18(2); Art. \#668, 5 pages. http:// dx.doi.org/10.4102/sajr. v18i2.668

\section{Copyright:}

(C) 2014. The Authors. Licensee: AOSIS

OpenJournals. This work is licensed under the Creative Commons Attribution License.
\end{abstract}

Read online:
This case report describes a juxta-articular myxoma (JAM) in an uncommon location, demonstrating an unusually aggressive local growth pattern.

\section{Introduction}

Myxomas are benign mesenchymal tumours characterised by the production of mucinous material in a scant spindle cell matrix. ${ }^{1}$ Juxta-articular myxoma (JAM) is a rare form of myxoma in the vicinity of a joint. ${ }^{2}$ JAM has an association with trauma or joint arthrosis. It is may be locally aggressive and commonly recurs after surgical excision. ${ }^{3}$

\section{Case presentation}

A 78-year-old man, with a history of colon carcinoma and gout, presented with a large mass in the thenar eminence and bilateral carpal tunnel syndrome. On clinical examination, the mass was fixed and had no inflammatory or infective features. Magnetic resonance imaging (MRI) was requested to assess the nature of the mass and exclude a neoplastic lesion.

\section{Imaging findings}

An extensive, multiseptated cystic mass was noted in the thenar eminence with infiltration around the flexor pollicis longis (FPL) and abductor pollicis brevis (APB) tendons. The mass had uniform fluid signal on proton density (PD) fat-saturated images (Figure 1 and Figure 2). Postcontrast images demonstrated enhancement of the septations with central fluid signal. Similar cystic infiltration was noted in and deep to the pronator quadratus (Figures 3b, 4, 5a and 5b).

Multiple osseous erosions involving the distal radius, the carpal bones and the metacarpal bases were observed. Prominent osseous erosion of the capitate and scaphoid was present with almost total destruction of the normal trabecular marrow. The erosions were PD hyperintense (Figure 1 and Figure 2), T1W hypointense (Figures 3a and Figure 6) and enhanced peripherally with almost uniform central fluid signal (Figures $3 b, 4,5 a$ and $5 b$ ). The erosions were sharply marginated and corticated and there was no associated bone marrow oedema.

Tenosynovitis was noted, involving all of the extensor and flexor compartments. The median nerve, compressed in the carpal tunnel, was oedematous and swollen proximal to the carpal tunnel (Figures 3b, 4, 5a and 5b). Prominent radiocarpal and intercarpal synovitis was present. Moderate arthrosis of the radiocarpal, first carpometocarpal (CMC) and scaphotrapeziotrapezoid (STT) joints. Periarticular fluid collections, synovitis and enhancing erosions were noted in relation to the metacarpophalangeal (MCP) joints.

A diagnosis of probable gout was made, with a differential diagnosis of polyarticular inflammatory arthritis. Metastatic disease was thought unlikely.

\section{Surgical findings}

At surgery, a complex, infiltrating, locally aggressive cystic mass was confirmed (Figure 7). The thenar mass was debulked, the carpal tunnel was released and a biopsy of the synovium of the radiocarpal joint was done.

\section{Histopathology}

Histology and immunohistological staining revealed a mucin-producing mass with scant spindle cells expressing smooth muscle actin and vimentin. No features of autoimmune synovitis were present and no crystals were found. S100 and desmin staining was negative. A pathological diagnosis of JAM was made. 


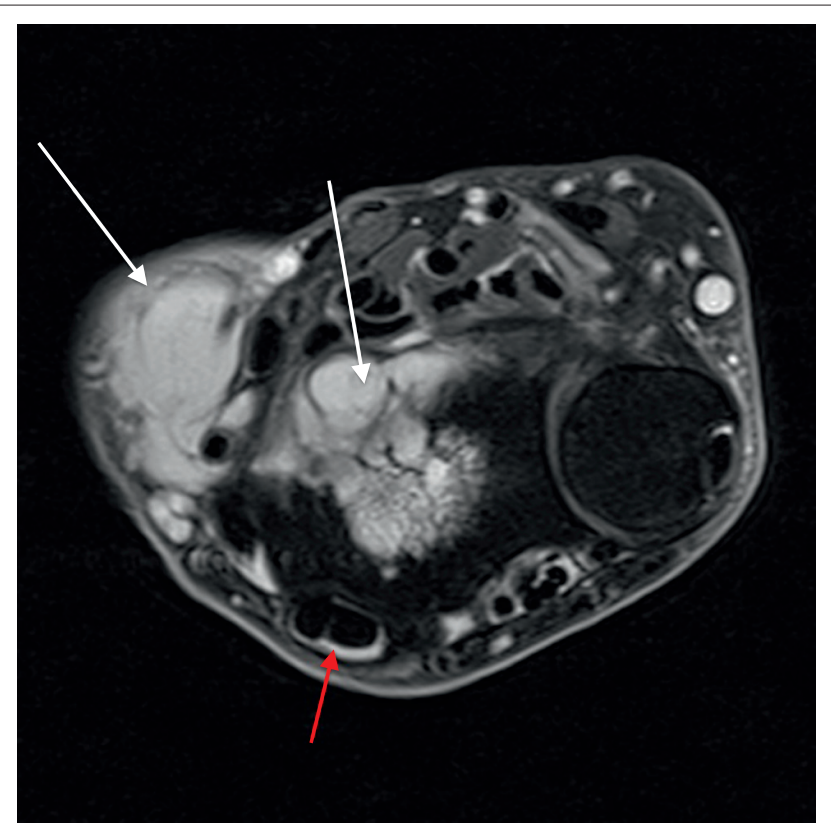

FIGURE 1: Axial PD fat-saturated image shows a cystic mass in the thena eminence extending into the pronator quadratus and the radial epiphysis (white arrows). There is widespread flexor and extensor tenosynovitis (red arrow).

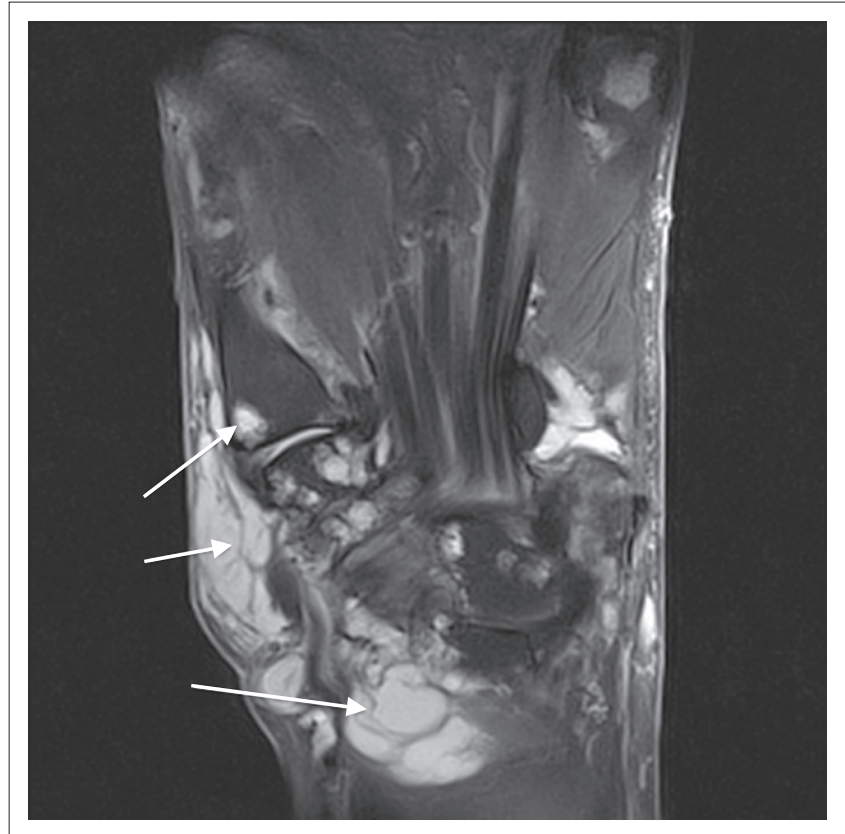

FIGURE 2: Coronal PD-weighted fat-saturated image shows a large, wellcircumscribed cystic mass in the thenar eminence with extensive infiltration into the adjacent carpal bones, distal radius and pronator musculature (white arrows).
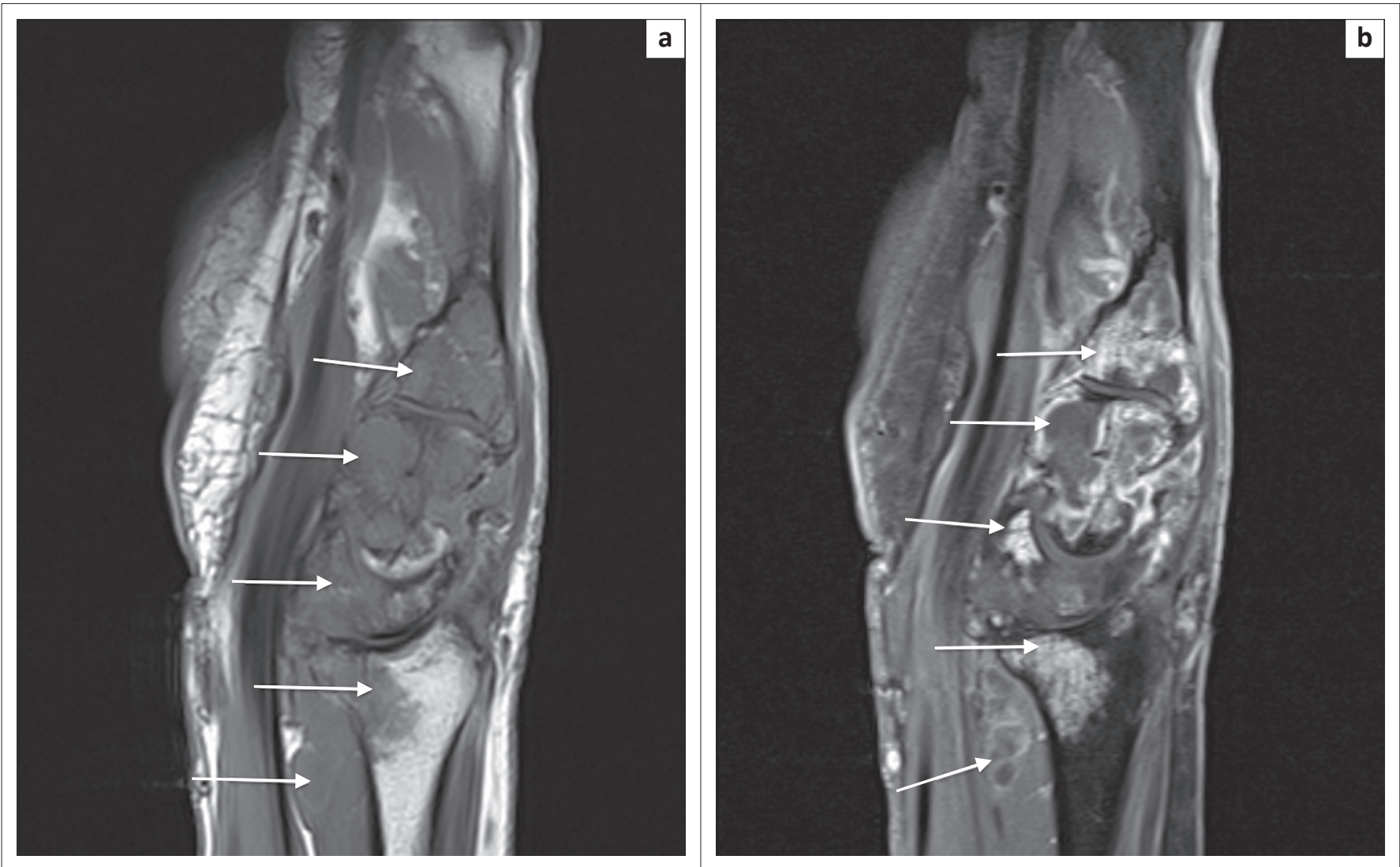

FIGURE 3: Sagittal T1 fast spin echo (FSE)-weighted images precontrast (a) and post contrast (b) demonstrate the pronator quadratus component and the intraosseous erosions in the radius, carpal bones and bases of the metacarpal bones. There is peripheral enhancement of the pronator mass, and intense solid and peripheral enhancement of the osseous erosions (white arrows).

\section{Clinical course}

The postoperative course was initially unremarkable; however, the patient returned four months later complaining of an increase in the size of the lesion, with decreasing left hand function. A repeat MRI was performed prior to further surgery, as dramatic clinical deterioration suggested a possible infectious or malignant diagnosis. 


\section{Follow-up MRI findings}

The MRI showed recurrence of the thenar eminence JAM, marked progression of the erosive intraosseous components, prominent flexor and extensor tenosynovitis, and radiocarpal and intercarpal synovitis (Figure 8).

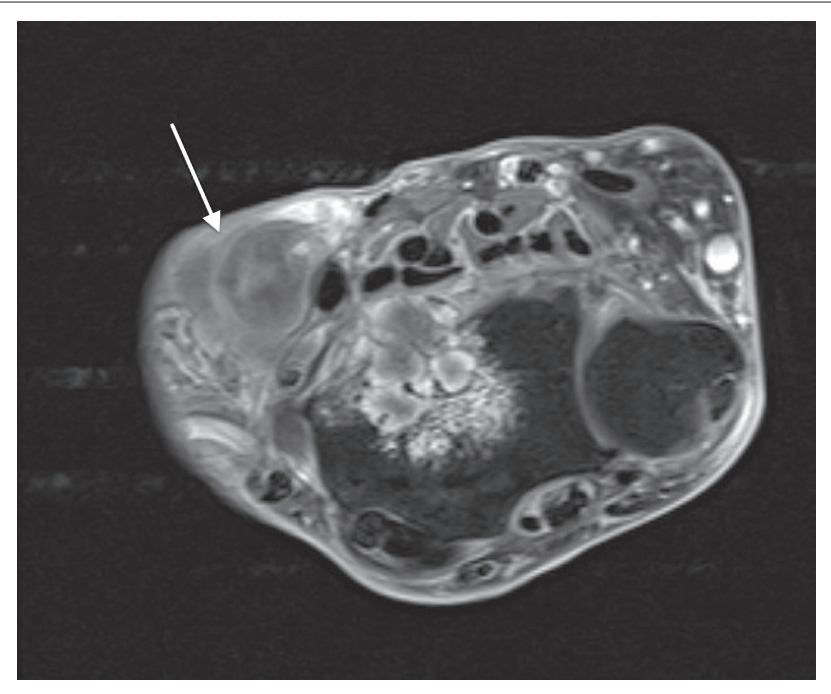

FIGURE 4: Axial T1-weighted fat-saturated image post intravenous gadolinium shows intense, predominantly peripheral, enhancement with central low T1 signal in the thenar mass (white arrow) and the radial erosion.

\section{Discussion}

JAM is most commonly associated with large joints, with a male preponderance. It is mostly found in the lower limbs, and is very unusual in the hand and wrist. ${ }^{5}$ JAM involves periarticular tissues including subcutaneous fat, joint capsule, tendons and rarely skeletal muscle.

The aetiology of the lesion is uncertain; however, there is an association with previous trauma and osteoarthrosis of the underlying joint. ${ }^{1,6}$ The lesion itself is usually painless, but it may cause local mechanical symptoms. JAMs do not metastasise; however, as in this case, they can be very locally aggressive. Postoperative recurrence is seen in approximately $30 \%$ of JAMs within five years of excision. ${ }^{3,4}$ Other types of myxoma are intramuscular, cutaneous aggressive angiomyxoma, and myxoma of the nerve sheath (neurothekeoma).

Intramuscular myxoma is the most commonly encountered myxoma in clinical practice, occurring in the thigh, upper arm and buttock. ${ }^{5}$ The lesion is characteristically a wellcircumscribed oval mass that is cystic in appearance. Intramuscular myxomas are usually solitary but may be multiple and, in this scenario, are usually associated with monostotic or polyostotic fibrous dysplasia, which is known as Mazabraud's syndrome. ${ }^{5}$

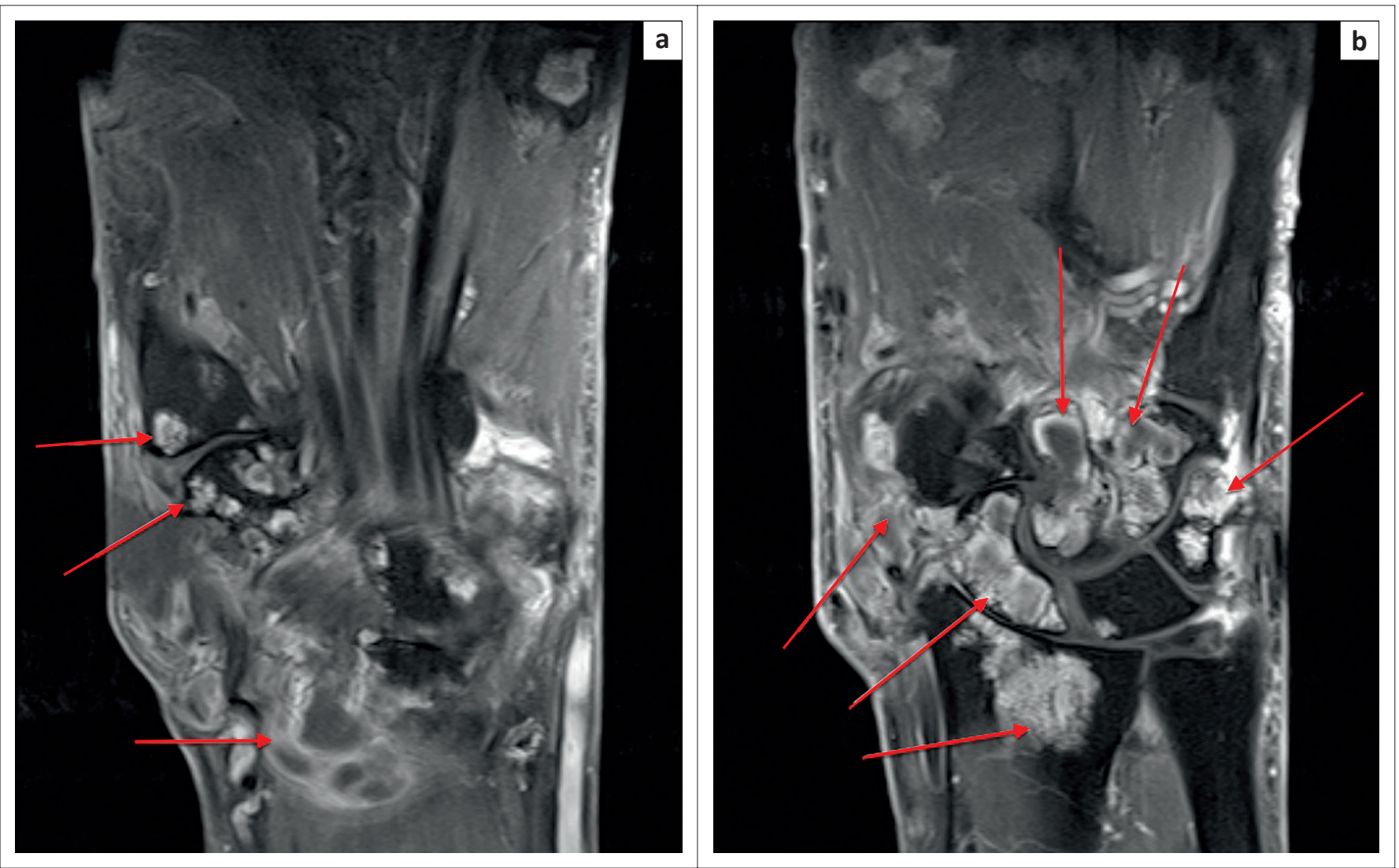

FIGURE 5: Coronal T1-weighted post intravenous gadolinium images ( $\mathrm{a}$ and $\mathrm{b}$ ). Intense, predominantly peripheral enhancement of the thenar mass and osseous erosions (red arrows). 


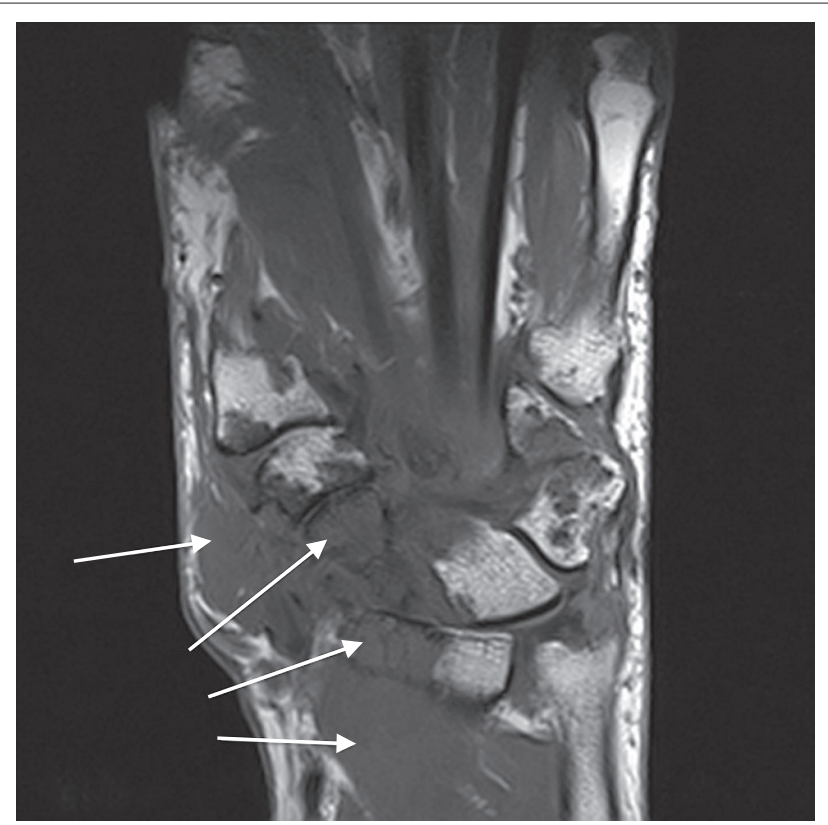

FIGURE 6: Coronal T1 FSE-weighted image shows an isointense lobulated mass in the thenar eminence with contiguous spread into the pronator quadratus, the radius, the carpal bones and the bases of the metacarpal bones (white arrows).

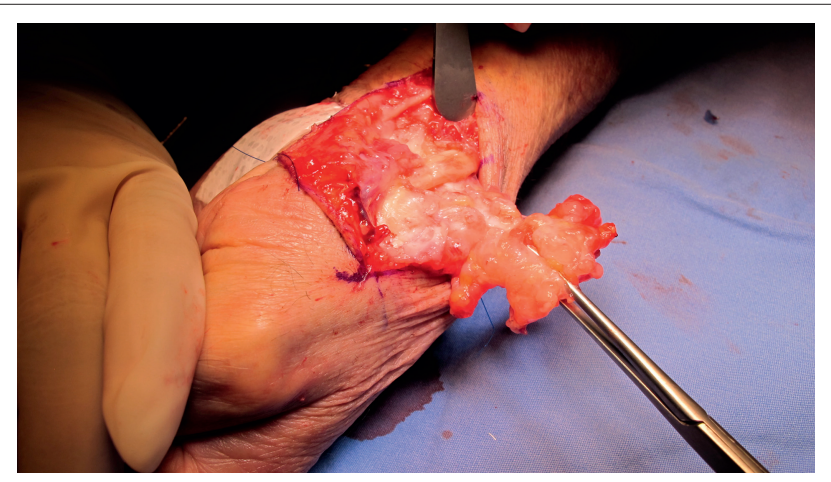

FIGURE 7: At surgery, a complex, infiltrating, locally aggressive cystic mass was confirmed.

On ultrasound, the lesion may appear as a complex cystic mass (hypo- or anechoic with increased throughtransmission and posterior acoustic enhancement) or may even appear solid. It is hypovascular. ${ }^{1}$ Computed tomography (CT) typically shows a lesion denser than water but less dense than muscle. ${ }^{8}$ The lesion on MRI is iso- to hypointense on precontrast $\mathrm{T} 1 \mathrm{~W}$, inhomogeneously hyperintense on $\mathrm{T} 2 \mathrm{~W}$, and demonstrates mild to moderate diffuse or peripheral contrast enhancement. ${ }^{8}$ Typical MRI findings also include mild perilesional oedema, owing to an incomplete fibrous capsule, and a split-fat sign as a result of adjacent muscle atrophy. ${ }^{8}$

JAM and intramuscular myxoma share the same histological characteristics, but are differentiated by lesion location and the high recurrence rate of JAM. The differential diagnosis of a lesion with imaging findings of a soft-tissue mass that mimics a cyst includes synovial cyst, bursa, ganglion, neurogenic neoplasms, myxoid liposarcomas and myxoid malignant fibrous histiocytoma (MFH) ${ }^{5,7}$
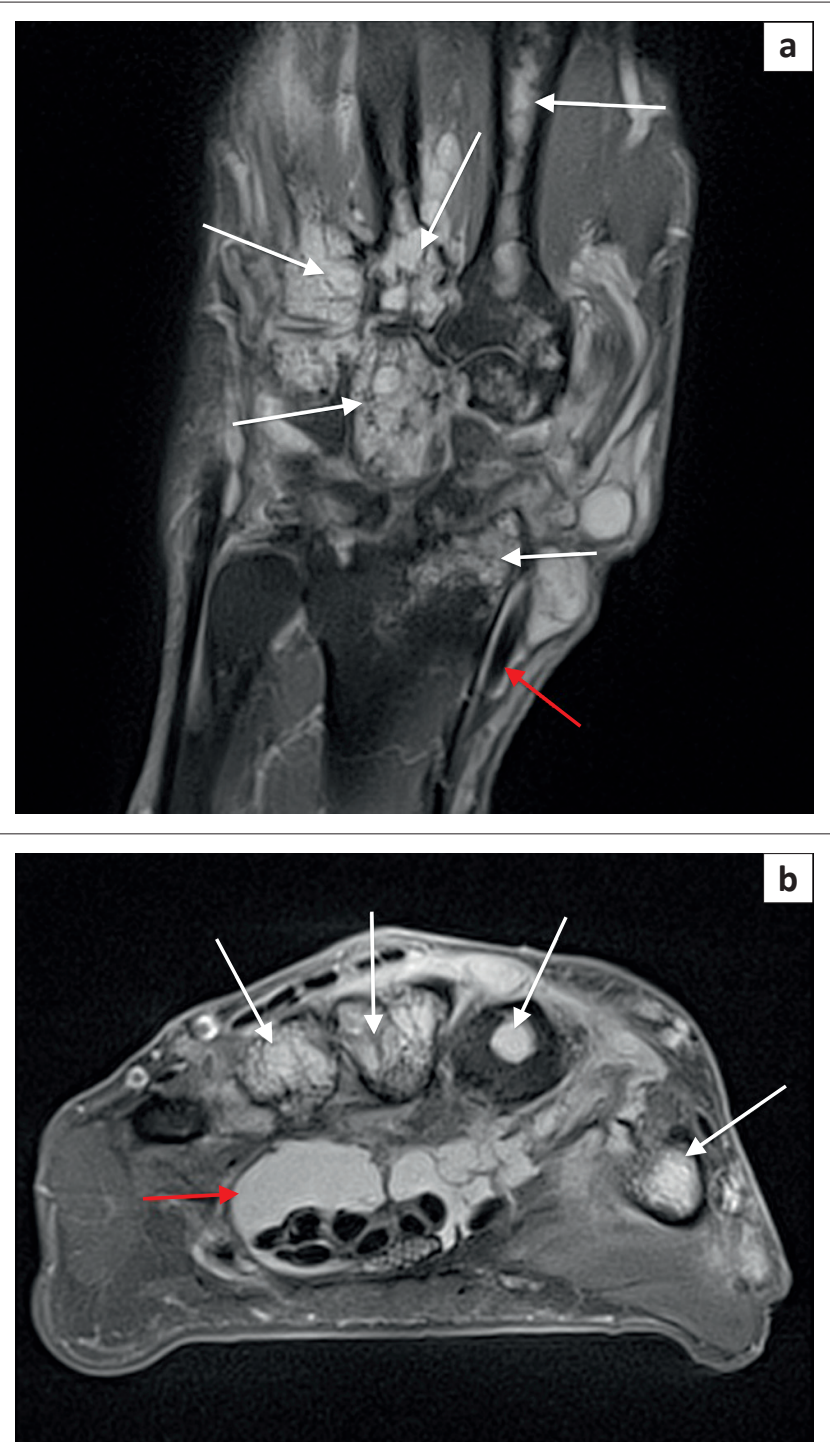

FIGURE 8: Coronal (a) and axial (b) PD fat-saturated images with marked flexor and extensor compartment tenosynovitis (red arrows) and large hyperintense erosions in the radius, carpal and metacarpal bones (white arrows).

\section{Conclusion}

JAM is a benign mesenchymal soft-tissue tumour that is a variant of myxoma, associated with large joints and joint degeneration. The present case demonstrates a histologically proven case of JAM in an unusual location, with an unusually aggressive growth pattern and prominent local tissue infiltration

\section{Acknowledgements}

\section{Competing interests}

The author declares that they he has no financial or personal relationships that he might have inappropriately influenced him in writing this article.

\section{References}

1. Meis JM, Enzinger FM. Juxta-articular myxoma: A clinical and pathologic study of 65 cases. Hum Pathol. 1992;23(6):639-646. http://dx.doi.org/10.1016/00468177(92)90319-X 
2. Allen PW. Myxoma is not a single entity: A review of the concept of myxoma. Ann Diagn Pathol. 2000;4(2):99-123. http://dx.doi.org/10.1016/S1092 9134(00)90019-4

3. Fletcher JW, Watson HK, Weinzweig J. Recurrent myxoma of the hand. J Hand Surg Am. 2000;25(4):772-775. http://dx.doi.org/10.1053/jhsu.2000.9412

4. Haluk OA, Merter Ozenski E, Inanc G, Serdar T. Juxta-articular myxoma of the wrist: A case report. J Hand Surg Am. 2005;30(1):165-167. http://dx.doi.org/10.1016/j. jhsa.2004.09.009

5. Murphey MD, McRae GA, Fanburg-Smith JC, Temple HT, Levine AM, Abouilafia AJ. Imaging of soft-tissue myxoma with emphasis on CT and MRI and comparison of radiologic and pathologic findings. Rad. 2002;225(1):215-224. http://dx.doi. org/10.1148/radiol.2251011627

6. Korver RJP, Theunissen PH, van de Kreeke WT, van der Linde MJ, Heyligers IC. Juxtaarticular myxoma in a 5-year-old boy: A case report and review of the literature. Eur Radiol. 2010;20(3):764-768. http://dx.doi.org/10.1007/s00330-00901490-7

7. Al-Qattan MM. Myxoma of the hand. J Hand Surg Br. 1996;21(5):690-692. http:// dx.doi.org/10.1016/S0266-7681(96)80163-X

8. Petscavage-Thomas JM, Walker EA, Logie $\mathrm{Cl}$, Clarke LE, Duryea DM, Murphey MD. Soft-tissue myxomatous lesions: Review of salient imaging features with pathologic comparison. Radiograph. 2014;34(4):964-980. http://dx.doi.org/10.1148/rg.344130110 